Original

\title{
Comparison of Past and Recent Historical Control Data in Relation to Spontaneous Tumors During Carcinogenicity Testing in Fischer 344 Rats
}

\author{
Ryo Ando ${ }^{1}$, Atsushi Nakamura ${ }^{1}$, Mariko Nagatani², Seiki Yamakawa ${ }^{2}$, \\ Toko Ohira ${ }^{2}$, Mizuho Takagi ${ }^{1}$, Keita Matsushima ${ }^{1}$, Ami Aoki ${ }^{1}$, \\ Yumiko Fujita ${ }^{1}$ and Kazutoshi Tamura ${ }^{1}$ \\ ${ }^{1}$ Pathology Division, Gotemba Laboratories, Bozo Research Center Inc., 1284 Kamado, Gotemba, Shizuoka 412-0039, \\ Japan \\ ${ }^{2}$ Hamamatsu Branch, Pathology Division, Bozo Research Center Inc., 164-2 Wada-cho, Hamamatsu, Shizuoka \\ 435-0016, Japan
}

\begin{abstract}
In the present survey, the historical data for spontaneous tumors observed in our laboratory was compared in relation to the time-related changes between recent (2000-2004) and past (1990-1999) samples from Fischer 344 rats used in carcinogenicity studies. In the recent samples, there were statistically increased incidences of islet cell adenomas in males and uterine adenocarcinomas in females. On the other hand, there were decreased incidences of pheochromocytomas, prostatic adenomas, pituitary anterior adenomas, large granular lymphocytic (LGL) leukemias and Leydig cell tumors in males and pituitary anterior adenomas in females. Furthermore, there were decreases in the body weights of both sexes at 58 weeks of age in the recent samples, and this may have been related to the decreases in the incidences of pheochromocytomas, Leydig cell tumors, prostatic adenomas and LGL leukemias. Moreover, the decreased incidence of pheochromocytoma in males revealed a positive correlation with a decreased percentage of severe chronic progressive nephropathy (CPN). On the other hand, there were no distinct factors responsible for increased incidences of tumors observed in the recent samples, suggesting a possible genetic drift. In conclusion, the incidences of spontaneous tumors obtained in our laboratory have been changed with time. Smaller body weights in both sexes and reduction in the number of male cases with severe CPN might be related to the reduced incidence of certain types of tumors in recent animals. (J Toxicol Pathol 2008; 21: 53-60)
\end{abstract}

Key words: historical control data, time-related change, neoplastic lesion, F344 rat, body weight, chronic progressive nephropathy

\section{Introduction}

It is important to maintain the validity of historical control data for assessment of toxicities, especially carcinogenicity. In carcinogenicity studies, Peto's test ${ }^{1,2}$ is commonly employed as one of the tools of statistical analysis for evaluation of the carcinogenicity of test chemicals; prior to analysis, the types of tumors observed must be categorized into common and rare tumors based on historical control data.

Tennekes et al. ${ }^{3,4}$ surveyed the stability of historical control data for common tumors in various strains of rats and

Received: 17 July 2007, Accepted: 16 October 2007

Mailing address: Ryo Ando, Pathology Division, Gotemba

Laboratories, Bozo Research Center Inc., 1284 Kamado, Gotemba,

Shizuoka 412-0039, Japan

TEL: 81-550-82-9914 FAX: 81-550-82-9915

E-mail: path@bozo.co.jp demonstrated that skin fibromas and malignant pheochromocytomas exhibited negative time trends, while benign pheochromocytomas and pancreatic islet cell adenomas exhibited positive time trends in male Fischer 344 rats.

Various factors, including $\operatorname{diet}^{5-15}$, body weight ${ }^{16-21}$, housing ${ }^{22,23}$ and certain kinds of morbidity such as chronic progressive nephropathy $(\mathrm{CPN})^{24}$, influence the occurrence of tumors. Nyska et al. ${ }^{24}$ suggested that there may be a positive correlation between the severity of $\mathrm{CPN}$ and the incidence of pheochromocytomas in Fischer 344 rats. In addition, a number of investigators have reported an association between tumor incidence and body weight in rodents ${ }^{16-21}$. Namely, Haseman et al. ${ }^{16}$ demonstrated an association between body weight during a 52 -week study period and the incidences of mammary gland and pituitary tumors in rats and the incidences of liver tumors in mice. They also mentioned that there was a negative correlation between the incidences of Leydig cell tumors and pituitary 
Table 1. Outline of the Studies in the Past and the Recent Groups

\begin{tabular}{|c|c|c|c|c|c|}
\hline \multirow[t]{2}{*}{ Data group } & \multirow[t]{2}{*}{ Study ID } & \multirow[t]{2}{*}{ Year of study start } & \multirow[t]{2}{*}{ Route of administration } & \multicolumn{2}{|c|}{ No. of rats } \\
\hline & & & & Male & Female \\
\hline \multirow[t]{12}{*}{ Past (1990-1999) } & $\# 1$ & 1991 & N.T. & 50 & 50 \\
\hline & $\# 2$ & 1992 & N.T. ${ }^{a)}$ & 238 & 238 \\
\hline & $\# 3$ & 1992 & N.T. & 100 & 100 \\
\hline & $\# 4$ & 1993 & N.T. and I.V. & $50+50$ & $50+50$ \\
\hline & $\# 5$ & 1993 & N.T. & 50 & 50 \\
\hline & $\# 6$ & 1993 & N.T. & 50 & 50 \\
\hline & $\# 7$ & 1993 & N.T. & 50 & 50 \\
\hline & $\# 8$ & 1994 & N.T. and P.O. & $55+55$ & $55+55$ \\
\hline & \#9 & 1994 & N.T. & 20 & 20 \\
\hline & $\# 10$ & 1995 & P.C. & 50 & 50 \\
\hline & \#11 & 1997 & P.O. & 55 & 55 \\
\hline & Total & & - & 873 & 873 \\
\hline Mean survival rate $(\%)$ & & & & $81.1^{\mathrm{b})}$ & $79.5^{c)}$ \\
\hline S.D. & & & & 5.5 & 8.0 \\
\hline \multirow[t]{6}{*}{ Recent (2000-2004) } & $\# 12$ & 2000 & P.O. & 55 & 55 \\
\hline & $\# 13$ & 2000 & P.O. & 55 & 55 \\
\hline & $\# 14$ & 2003 & P.O. & 55 & 55 \\
\hline & $\# 15$ & 2003 & P.O. & 55 & 55 \\
\hline & \#16 & 2004 & S.C. & 55 & 55 \\
\hline & Total & & - & 275 & 275 \\
\hline Mean survival rate $(\%)$ & & & & $85.1^{\mathrm{b})}$ & $74.5^{\mathrm{c})}$ \\
\hline S.D. & & & & 4.2 & 5.0 \\
\hline
\end{tabular}

N.T.: None treated (feeding).

I.V.: Intravenous administration.

P.O.: Peroral administration.

P.C.: Percuteneous administration.

S.C.: Subcutaneous administration.

a): This consisted of 5 different batches.

b), c): No significant difference between the groups.

tumors in male Fischer 344 rats. Moreover, Seilkop et al. ${ }^{19}$ reported that there was a positive relationship between body weight and the risk of pituitary and mammary gland tumors in rats. Nyska et al. ${ }^{23}$ studied the effect of caging on spontaneous tumor occurrence and suggested that individual caging might promote pituitary and Leydig cell tumors due to stress-induced hormonal imbalances.

In the present study, to evaluate the difference in historical control data for spontaneous tumors between past and recent samples from Fischer 344 rats in our laboratory, the tumor incidence data form recent studies (2000-2004) were compared with those of past studies (1990-1999). Moreover, the factors that appear to influence spontaneous tumor occurrence were analyzed.

\section{Materials and Methods}

\section{Animals}

A total of 1148 male and 1148 female F344/DuCrlCrlj strain rats (Charles River Japan Inc., Atsugi, Kanagawa, Japan) obtained from the control groups of 14 carcinogenicity studies and 2 background data-collection studies were examined (Table 1). Except for the background data-collection studies, each study had one or two control groups. All studies were conducted in our laboratory between 1990 and 2004. These studies were divided into two groups; the recent data group composed of 5 studies (a total of 275 males and 275 females) from between 2000 and 2004 and the past data group composed of 11 studies (a total of 873 males and 873 females) from between 1990 and 1999. The animals were housed individually in bracket-type stainless-steel wire mesh cages and were maintained in barrier-sustained rooms at $23 \pm 3^{\circ} \mathrm{C}$, at a relative humidity of $50 \pm 20 \%$, with air ventilation 10 to 15 times per hour and with artificial lighting for 12 hours per day. The animals were allowed free access to CRF-1 diet (Oriental Yeast Co., Ltd., Tokyo, Japan) and tap water.

Each study was carried out in accordance with the Guide for Animal Experimentation of Bozo Research Center Inc.

\section{Histopathology data analysis}

Prior to the present analysis, all neoplastic and preneoplastic lesions were reviewed by one pathologist in order to ensure consistency of the diagnostic criteria. Tumors showing incidences of more than $5 \%$ in either the 
Table 2. Comparison of Tumor Incidence in Male Fischer 344 Rats

\begin{tabular}{|c|c|c|c|}
\hline & $\begin{array}{l}\text { Data group } \\
\text { No. of rats }\end{array}$ & $\begin{array}{c}\text { Past (1990-1999) } \\
873\end{array}$ & $\begin{array}{c}\text { Recent }(2000-2004) \\
275\end{array}$ \\
\hline \multirow[t]{2}{*}{ Prostatic adenoma } & Mean (\%) & 16.8 & $10.6^{b)}$ \\
\hline & Range (\%) & $4-28$ & $7-15$ \\
\hline \multirow[t]{2}{*}{ Leydig cell tumor } & Mean (\%) & 92.9 & $85.5^{\mathrm{b})}$ \\
\hline & Range (\%) & $76-98$ & $78-91$ \\
\hline \multirow[t]{2}{*}{ Pituitary anterior adenoma } & Mean $(\%)$ & 28.0 & $20.0^{\mathrm{b})}$ \\
\hline & Range (\%) & $13-52$ & $13-31$ \\
\hline \multirow[t]{2}{*}{ Adrenal pheochromocytoma } & Mean $(\%)$ & 15.5 & $7.3^{b)}$ \\
\hline & Range (\%) & $7-22$ & $2-13$ \\
\hline \multirow[t]{2}{*}{ Large granular lymphocytic leukemia } & Mean $(\%)$ & 19.1 & $13.1^{\mathrm{a})}$ \\
\hline & Range (\%) & $4-30$ & $7-20$ \\
\hline \multirow[t]{2}{*}{ Hepatocellular adenoma } & Mean (\%) & 5.0 & 3.6 \\
\hline & Range (\%) & $0-12$ & $0-7$ \\
\hline \multirow[t]{2}{*}{ Islet cell adenoma } & Mean $(\%)$ & 10.5 & $17.1^{\mathrm{b})}$ \\
\hline & Range (\%) & $0-18$ & $9-25$ \\
\hline \multirow[t]{2}{*}{ Cutaneous fibroma } & Mean $(\%)$ & 4.6 & 5.8 \\
\hline & Range (\%) & $0-10$ & $2-9$ \\
\hline \multirow[t]{2}{*}{ Tyroid C-cell adenoma } & Mean (\%) & 17.4 & 20.1 \\
\hline & Range (\%) & $6-25$ & $13-27$ \\
\hline
\end{tabular}

a): Significantly different from the past group at $\mathrm{P}<0.05$.

b): Significantly different from the past group at $\mathrm{P}<0.01$.

Table 3. Comparison of Tumor Incidence in Female Fischer 344 Rats

\begin{tabular}{lccc}
\hline & Data group & Past (1990-1999) & Recent (2000-2004) \\
& No. of rats & 873 & 275 \\
\hline Uterine endometrial stromal polyp & Mean (\%) & 31.0 & 29.1 \\
& Range (\%) & $18-44$ & $24-35$ \\
Uterine adenocarcinoma & Mean (\%) & 3.3 & $12.0^{\text {b) }}$ \\
& Range (\%) & $0-8$ & $9-16$ \\
Pituitary anterior adenoma & Mean (\%) & 37.5 & $29.9^{\text {a }}$ \\
& Range (\%) & $29-52$ & $27-31$ \\
Mammary fibroadenoma & Mean (\%) & 6.5 \\
Large granular lymphocytic leukemia & Range (\%) & $2-15$ & $2-15$ \\
& Mean (\%) & 21.3 & 20.7 \\
Tyroid C-cell adenoma & Range (\%) & $5-34$ & $13-27$ \\
& Mean (\%) & 11.5 & 11.8 \\
\hline
\end{tabular}

a): Significantly different from the past group at $\mathrm{P}<0.05$.

b): Significantly different from the past group at $\mathrm{P}<0.01$.

recent or past historical control data or both were analyzed. The tumors analyzed included prostatic adenomas, Leydig cell tumors, pituitary anterior adenomas, pheochromocytomas, large granular lymphocyte (LGL) leukemias, hepatocellular adenomas, islet cell adenomas, skin fibromas and $\mathrm{C}$ cell adenomas in males (Table 2) and uterine endometrial stromal polyps, uterine adenocarcinomas, pituitary anterior adenomas, mammary fibroadenomas, LGL leukemias and $\mathrm{C}$ cell adenomas in females (Table 3 ). The incidences of these tumors were examined in relation to body weight at 58 weeks of age. Moreover, to examine the potential association between the incidence of pheochromocytoma and severity of the CPN, the male animals were divided into two groups: a group with no or mild CPN and a group with moderate or severe CPN.

\section{Statistical analysis}

The incidences of neoplastic lesions were analyzed by Fisher's exact probability test. After estimation of the survival curves by the Kaplan-Meier method, the difference in the survival rates between the data for the recent and past historical samples were compared using log-rank test (level of significance: $5 \%$ in a one-tailed level). Food consumption was analyzed by the Aspin-Welch t-test for heterogeneity of variance between the data for the recent and past historical samples. Body weight was analyzed by Bartlett's test for homogeneity of variance between the data for the recent and past historical samples. If the variances were homogeneous 
Table 4. Weight Categories Used in Moving Average Calculations at 58 Weeks of Age

\begin{tabular}{|c|c|c|c|c|c|}
\hline \multicolumn{6}{|c|}{ Weight range (g) evaluated ${ }^{a)}$} \\
\hline & First & Second & Third & Penultimate & Final \\
\hline Male & $<340$ & $340-360$ & $341-361$ & $460-480$ & $>480$ \\
\hline Female & $<200$ & $200-220$ & $201-221$ & $250-270$ & $>270$ \\
\hline
\end{tabular}

a): The number of animals per weight range category typically varied from 50 to 250 for male rats and from 40 to 160 for female rats; the total number of weight range categories was 123 for male rats and 53 for female rats.

or heterogeneous, Dunnett's tests for parametric or nonparametric multiple comparisons were performed, respectively. To investigate the association between tumor occurrence and body weight, the moving average method, established by Haseman et al. ${ }^{16}$, was employed to calculate the tumor incidence for animals falling into selected 58 week-old body weight categories using all animals from the recent and past data groups. The weight ranges used are summarized in Table 4. Application of the moving average approach allowed smoothing of the data and simple graphical representation of the observed relationship between the tumor incidence and body weight.

\section{Results}

\section{Changes in tumor frequency with time}

There were significant negative time trends for prostatic adenomas (from $16.8 \%$ to $10.6 \%, \mathrm{P}<0.01$ ), Leydig cell tumors (from $92.9 \%$ to $85.5 \%, \mathrm{P}<0.01$ ), pituitary anterior adenomas (from $28.0 \%$ to $20.0 \%, \mathrm{P}<0.01$ ), adrenal pheochromocytomas (from $15.5 \%$ to $7.3 \%, \mathrm{P}<0.01$ ) and LGL leukemias (from $19.1 \%$ to $13.1 \%, \mathrm{P}<0.05$ ) in males (Table 2) and pituitary anterior adenomas (from $37.5 \%$ to $29.9 \%, \mathrm{P}<0.05$ ) in females (Table 3 ). On the other hand, there were significantly positive time trends for pancreatic islet cell adenomas (from $10.5 \%$ to $17.1 \%, \mathrm{P}<0.01$ ) in males (Table 2) and uterine adenocarcinomas (from 3.3\% to $12.0 \%, \mathrm{P}<0.01$ ) in females (Table 3 ).

\section{Changes in body weight with time}

The body weight data for the recent and past data groups are shown in Fig. 1A. The average body weight of the recent group was significantly lower than that of the past group.

\section{Food consumption}

The food consumption of the recent and past data groups is shown in Fig. 1B. The food consumption of the recent study group was significantly lower than that of the past one.

\section{Survival rate}

The survival rates of the recent and past groups are shown in Table 1.

There was no significant difference in survival rate between the past and recent study groups (Table 1).
Tumor incidence and body weight at 58 weeks of age

The incidences of Leydig cell tumors in males (Fig. 2A) and pituitary anterior adenomas in females (Fig. 3A) decreased in parallel with a decrease in body weight at 58 weeks of age. Similarly, the incidences of prostatic adenomas (Fig. 2B), pituitary anterior adenomas (Fig. 2C), adrenal pheochromocytomas (Fig. 2D) and LGL leukemias (Fig. 2E) in males decreased in parallel with a decrease in body weight at 58 weeks of age. Also, the recent groups exhibited decreases in the incidences of these tumors (Tables 2 and 3 ). In contrast, the incidence of uterine adenocarcinomas in females (Fig. 3B) increased with a decrease of body weight at 58 weeks of age, indicating an increase in the incidence of this tumor in the recent data (Table 3). In regard to islet cell tumor in males (Fig. 2F), there was no association between its incidence and body weight at 58 weeks of age.

\section{Change in the severity of $C P N$}

In the recent group of animals, both the overall incidence of CPN and the ratio of cases with a moderate or severe degree of CPN exhibited decreases compared with the past group (Table 5).

\section{Incidence of pheochromocytoma and severity of CPN}

The incidence of pheochromocytoma in the cases with moderate or severe $\mathrm{CPN}$ was higher than that in the cases with no or mild CPN (25.0\% for moderate or severe CPN and $13.1 \%$ for no or mild $\mathrm{CPN}, \mathrm{P}<0.001$; Table 6 ).

\section{Discussion}

In order to enable accurate assessment of the toxicity and carcinogenicity of chemicals, historical control data should be updated regularly because spontaneous lesions change over time. The present survey of long-term studies using Fischer 344 rats in our laboratory revealed that the incidences of islet cell adenomas in males and uterine adenocarcinomas in females increased, while those of prostatic adenomas, Leydig cell tumors, pituitary anterior adenomas, adrenal pheochromocytomas and LGL leukemias in males and pituitary anterior adenomas in females decreased in the recent group of animals as compared with those in the past group.

Tumor generation is influenced by various factors, including $\operatorname{diet}^{5-15}$ (nutrient composition, caloric intake and 

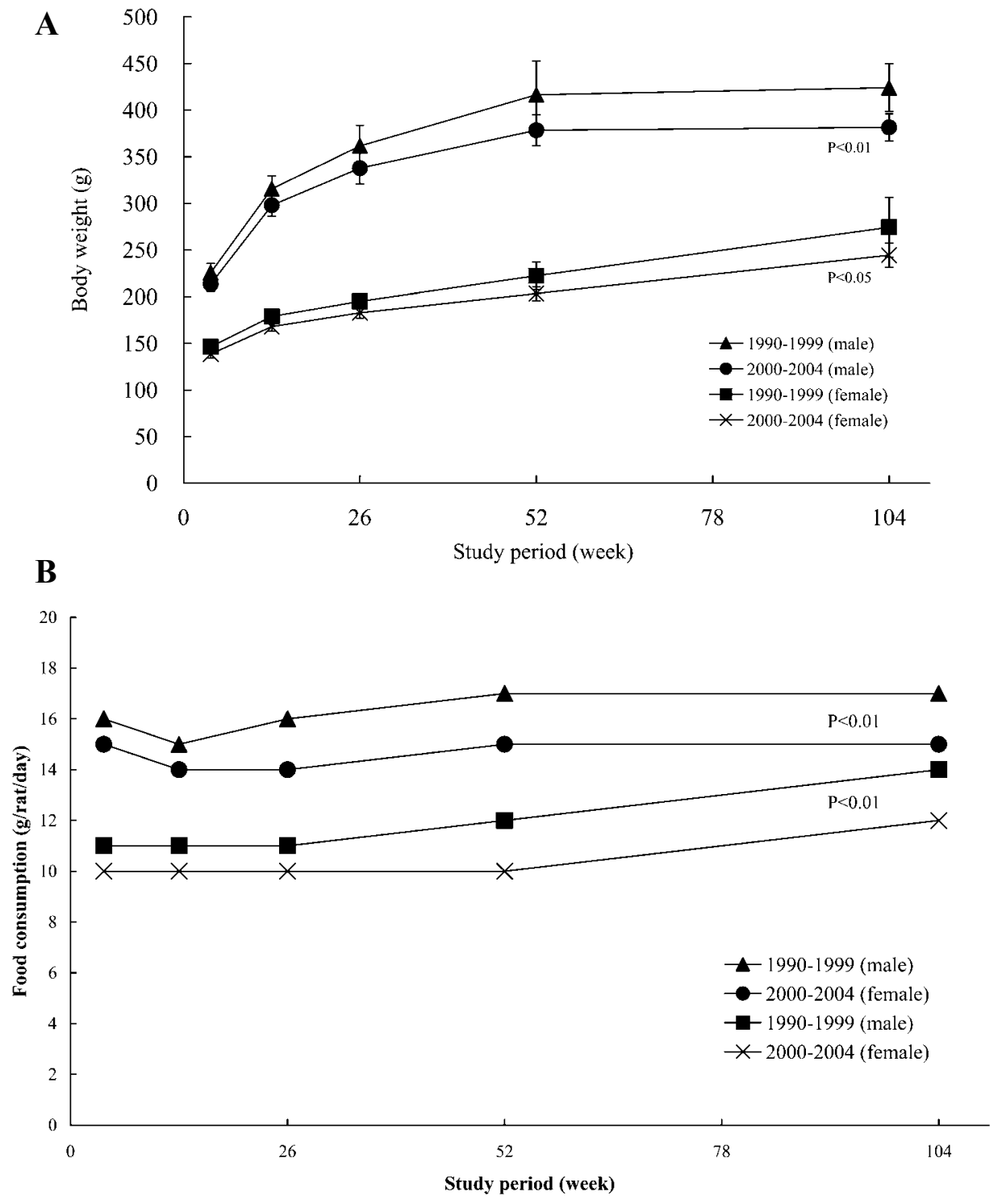

Fig. 1. Comparison of body weight (A) and food consumption (B) between the past and recent study groups.

food intake), body weight ${ }^{16-21}$, housing ${ }^{22,23}$ and certain kinds of morbidity such as $\mathrm{CPN}^{24}$. In regard to the studies included in the present survey, there were no differences in diet composition or housing conditions. However, the food consumption of the recent group was lower than that of the past group in the present survey, and this difference may have had an effect on the lower body weights in the recent data.

In relation to humans, Doll et al. ${ }^{25}$ reported that the adult body weight is correlated with development of colorectal, lung, endometrial, cervical, breast and gallbladder cancers. In relation to animals, Haseman et al. ${ }^{16}$ demonstrated that increased body weight during a 52-week study period is associated with increased incidences of pituitary and mammary gland tumors in Fischer 344 rats, and Rao et al. ${ }^{17,18}$ reported that there are highly positive correlations between the incidences of mammary tumors in females and pituitary tumors in males and body weight. In the present survey, body weight decreased in the recent data compared with the past data. Judging from the results analyzed by the moving average method using body weight at 58 weeks of age as a variable, decreased body weight in the recent group appeared to be related to decreased incidences of adrenal pheochromocytomas, Leydig cell tumors, prostatic adenomas and LGL leukemias in males and pituitary anterior adenomas in females.

On the other hand, the incidence of uterine adenocarcinomas significantly increased in the recent group animals, although we could not identify any reasonable explanations for this observation at present. Nyska et al. ${ }^{26}$ reported that the incidence of spontaneously occurring uterine endometrial adenocarcinomas observed in their laboratory increased compared with those of their previous study, which was conducted under similar conditions, and 

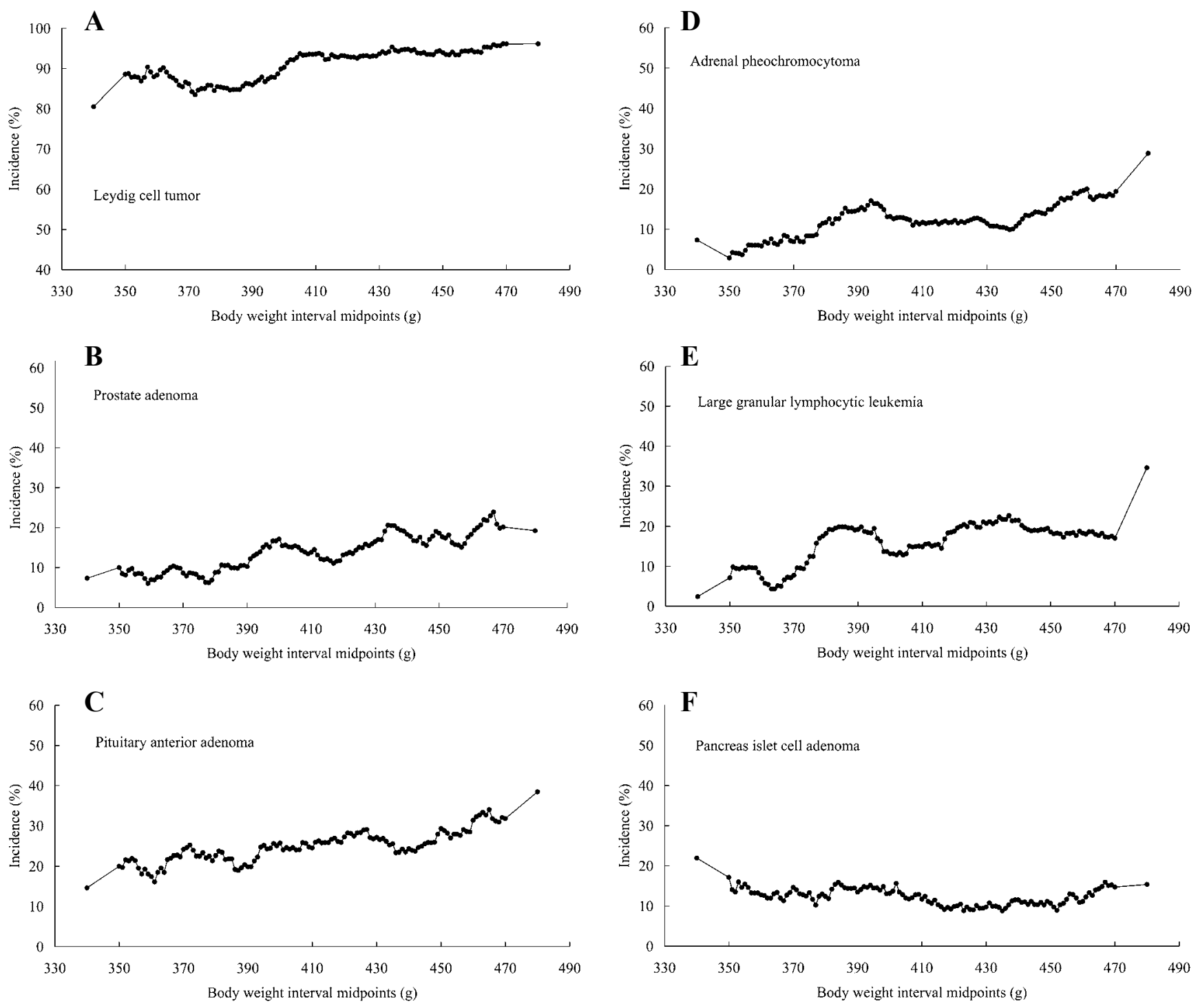

Fig. 2. Association between tumor incidences and body weight at 58 weeks of age in male Fischer 344 rats. Each point indicates the midpoint of the body weight range. A: Leydig cell tumor B: prostatic adenoma C: pituitary anterior adenoma D: adrenal pheochromocytoma E: LGL leukemia F: islet cell tumor.
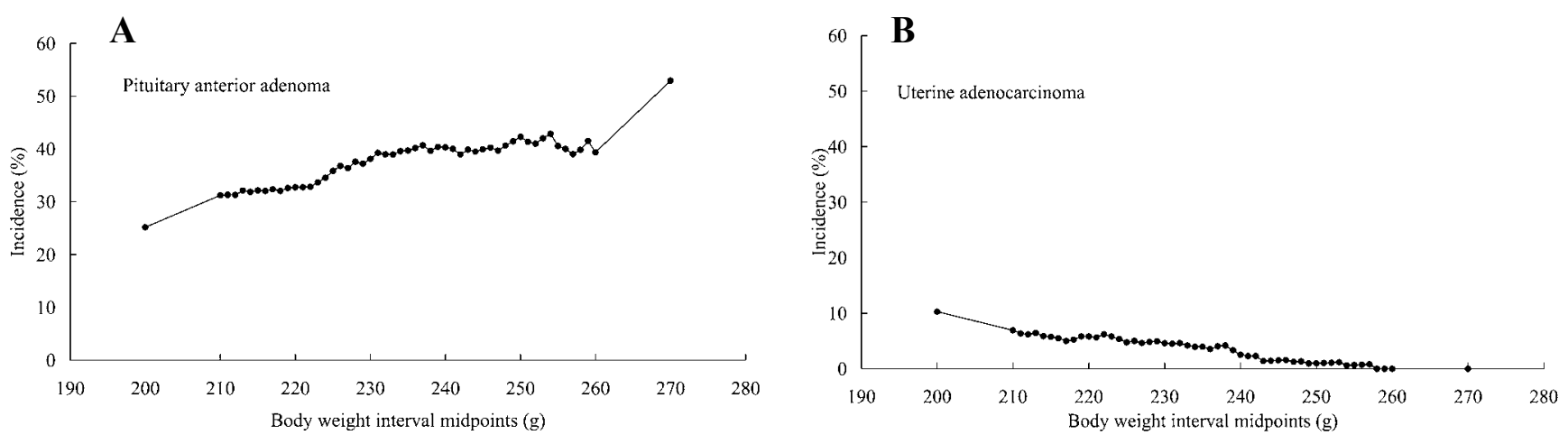

Fig. 3. Association between tumor incidences and body weight at 58 weeks of age in female Fischer 344 rats. Each point indicates the midpoint of the body weight range. A: pituitary anterior adenoma B: uterine adenocarcinoma 
Table 5. Comparison of the Incidence of Chronic Progressive Nephropathy Between the Past and the Recent Data

\begin{tabular}{lrrrr}
\hline & \multicolumn{2}{c}{ Past } & \multicolumn{2}{c}{ Recent } \\
\multicolumn{1}{c}{ Data group } & $(1990-1999)$ & $(2000-2004)$ \\
No. of rats & 873 & $\%$ & 275 & $\%$ \\
\hline Chronic progressive nephropathy & 819 & 93.8 & 246 & $89.5^{\text {a) }}$ \\
Unremarkable & 54 & 6.2 & 29 & $10.5^{\text {a) }}$ \\
Mild & 655 & 75.0 & 242 & $88.0^{\text {b) }}$ \\
Moderate/severe & 164 & 18.8 & 4 & $1.5^{\text {b) }}$ \\
\hline
\end{tabular}

a): Significantly different from the past group at $\mathrm{P}<0.05$.

b): Significantly different from the past group at $\mathrm{P}<0.01$.

Table 6. Association between Occurrence of Pheochromocytoma and Severity of Chronic Progressive Nephropathy

\begin{tabular}{ccccc}
\hline & \multicolumn{3}{c}{ Chronic Progressive } & \multicolumn{3}{c}{ Nephropathy } \\
Severity & \multicolumn{2}{c}{ None/mild } & \multicolumn{2}{c}{ More severe } \\
No. of rats & 980 & $\%$ & 168 & $\%$ \\
\hline Pheochromocytoma bearers & 128 & 13.1 & 42 & $25.0^{\text {a) }}$ \\
\hline
\end{tabular}

a): Significantly different from the none/mild chronic progressive nephropathy group $(\mathrm{P}<0.01)$.

NTP background data. They found no association between the incidence of uterine adenocarcinomas and the presence of pituitary neoplasms, mammary neoplasms, uterine endometrial hyperplasias and uterine inflammations. Similarly, in our present survey, there was no association between the incidence of adenocarcinomas and the presence of other lesions in females (data not shown).

$\mathrm{CPN}$, a common age-related lesion in male rats, is known to exert secondary effects on tumorigenesis. Nyska et $a .^{24}$ suggested the possibility that the severity of CPN is positively correlated with the rate of production of pheochromocytoma in male Fischer 344 rats, although this is somewhat controversial among researchers. In animals with severe CPN, calcium/phosphorous homeostasis is severely disturbed. This provokes a secondary hyperparathyroidism, leading to an increase in the serum $\mathrm{Ca}^{2+}$ level ${ }^{27}$. It has been suggested that this perturbation of calcium homeostasis stimulates chromaffin cell proliferation and leads to induction of adrenal medullary tumors ${ }^{28-30}$. Kurokawa et $a l .{ }^{31}$ reported an association between hypercalcemia and increased incidence of pheochromocytoma in rats. The present results also confirmed that there was a clear correlation between the severity of CPN and the incidence of pheochromocytoma.

The present study demonstrated that the historical control data for spontaneous tumors in Fischer 344 rats in our laboratory has changed with time. The decreased incidences of tumors in the recent data seems to be, in part, related to decreases in both body weight and the severity of CPN. In contrast, there were no relevant factors responsible for tumors for which the incidences increased. Tennekes $e t$ $a l .{ }^{3}$ suggested that changes in the incidences of tumors might be caused by genetic drift, although genetic changes are rare in inbred Fischer 344 rats, which we used in the present survey, compared with outbred Wistar and Sprague-Dawley rats.

Acknowledgement: The authors wish to thank Dr. Kunio Doi, Emeritus Professor of the University of Tokyo, for review of this manuscript. We also thank Mr. Tomoyoshi Katsumata for assistance with statistical analysis.

\section{References}

1. Peto R, Pike MC, Day NE, Lee PN, Parish S, Peto J, Richard $\mathrm{S}$, and Wahrendorf J. Guidelines for simple, sensitive tests for carcinogenic effects in long-term animal experiments. IARC Monographs on the Evaluation of the Carcinogenic Risk of Chemicals to Humans. Suppl. 2: 365-367. 1980.

2. Guidance for industry: Statistical aspect of the design, analysis, and interpretation of chronic rodent carcinogenidity studies of pharmaceuticals. Draft guidance. U.S. Department of Health and Human Services, FDA, and CDER. 2001.

3. Tennekes $\mathrm{H}$, Gembardt $\mathrm{C}$, Dammann $\mathrm{M}$, and van Ravenzwaay B. The stability of historical control data for common neoplasms in laboratory rats: adrenal gland (medulla), mammary gland, liver, endocrine pancreas and pituitary gland. Regul Toxicol Pharmacol. 40: 18-27. 2004.

4. Tennekes H, Kaufmann W, Dammann M, and van Ravenzwaay B. The stability of historical control data for common neoplasms in laboratory rats and the implications for carcinogenic risk assessment. Regul Toxicol Pharmacol. 40: 293-304. 2004.

5. Roe FJC, Lee PN, Conybeare G, Kelly D, Matter B, Prentice D, and Tobin G. The biosure study: Influence of composition of diet and food consumption on longevity, degenerative disease and neoplasia in Wistar rats. Food Chem Toxicol. 33 (Suppl 1): 1S-100S. 1995.

6. Haseman JK. Statistical considerations in long term dietary restriction studies. In: Dietary Restriction: Implications for the Design and Interpretation of Toxicity and Carcinogenicity studies. R Hart, D Neumann, and R Robertson (eds). ILSI Press, Washington D.C. 141-154. 1995.

7. Kari F and Abdo K. The sensitivity of the NTP bioassay for carcinogen hazard evaluation can be modulated by dietary restriction. In: Dietary Restriction: Implications for the Design and Interpretation of Toxicity and Carcinogenicity Studies. R Hart, D Neumann, and R Robertson (eds). ILSI press, Washington D.C. 63-78. 1995.

8. Thurman JD, Bucci TJ, Hart RW, and Turturro A. Survival, body weight, and spontaneous neoplasms in ad libitum-fed and food-restricted Fischer 344 rats. Toxicol Pathol. 22: 1-9. 1994.

9. Witt WM, Sheldon WG, and Thurman JD. Pathological endpoints in dietary restricted rodents: Fischer 344 rats and B6C3F1 mice. In: Biological Effects of Dietary Restriction. In: Biological Effects of Dietary Restriction. L Fishbein (ed). Springer-Verlag, New York. 73-86. 1991.

10. Molon-Noblot S, Laroque $\mathrm{P}$, Coleman JB, Hoe $\mathrm{CH}$, and Keenan KP. The effects of ad libitum overfeeding and moderate and marked dietary restriction on age-related spontaneous pituitary gland pathology in Spraque-Dawley 
rats. Toxicol Pathol. 31: 310-320. 2003.

11. Tucker M. The effect of long-term food restriction on tumors in rodents. Int J Cancer. 23: 803-807. 1979.

12. Tannenbaum A. The initiation and growth of tumors. I Effect of underfeeding. Am J Cancer. 38: 335-350. 1940.

13. Ross $\mathrm{MH}$ and Bras G. Lasting influence of early caloric restriction on prevalence of neoplasms in the rat. J Natl Cancer Inst. 47: 1095-1113. 1971.

14. Ross $\mathrm{MH}$ and Bras $\mathrm{G}$. Influence of protein under- and overnutrition on spontaneous tumor prevalence in the rat. $\mathrm{J}$ Nutr. 103: 944-963. 1973.

15. Pollard M, Luckert PH, and Synder D. Prevention of prostate cancer and liver tumors in L-W rats by moderate dietary restriction. Cancer. 64: 686-690. 1989.

16. Haseman JK, Young E, Eustis S, and Hailey JR. Body weight-tumor incidence correlations in long-term rodent carcinogenicity studies. Toxicol Pathol. 25: 256-263. 1997.

17. Rao GN, Piegorsch WW, and Haseman JK. Influence of body weight on the incidence of spontaneous tumors in rats and mice of long-term studies. Am J Clin Nutr. 45: 252-260. 1987.

18. Rao GN, Haseman JK, Grumbein S, Crawford D, and Eustis SL. Growth, body weight, survival, and tumor trends in F344/N rats during an eleven-year period. Toxicol Pathol. 18: 61-70. 1990.

19. Seilkop SK. The effect of body weight on tumor incidence and carcinogenicity testing in B6C3F1 mice and F344 rats. Fundam Appl Toxicol. 24: 247-259. 1995.

20. Ross MH, Lustbader ED, and Bras G. Influence of body weight and growth to resk of anterior pituitary gland tumors of the rat. J Natl Cancer Inst. 70: 1119-1125. 1983.

21. Ross MH, Lustbader ED, and Bras G. Body weight, dietary practices, and tumor susceptibility in the rat. J Natl Cancer Inst. 71: 1041-1046. 1983.

22. Haseman JK, Bourbina J, and Eustis S. The effect of individual housing and other experimental design factors on tumor incidence in B6C3F1 mice. Fund Appl Toxicol. 23: 44-52. 1994.

23. Nyska A, Leininger JR, Maronpot RR, Haseman JK, and Hailey JR. Effect of individual versus group caging on the incidence of pituitary and Leydig cell tumors in F344 rats: proposed mechanism. Med Hypothesis 50: 525-529. 1998.

24. Nyska A, Haseman JK, Hailey JR, Smetana S, and Maronpot RR. The association between severe nephropathy and pheochromocytoma in the male F344 rat - The National Toxicology Program experience. Toxicol Pathol. 27: 456462. 1999.

25. Doll $\mathrm{R}$ and Peto R. The causes of cancer: quantitative estimates of avoidable risks of cancer in the United States today. J Natl Cancer Inst. 66: 1191-1308. 1981.

26. Nyska A, Klein $T$, Scolnik $M$, Waner $T$, and Klein B. Unusually high incidence of spontaneous endometrial adenocarcinoma in aged virgin Fischer rats. Exp Toxic Pathol. 46: 7-9. 1994.

27. Cotran RS, Kumar V, and Robins SL. Cellular injury and cellular death. In: Pathologic Basis of Disease. $5^{\text {th }}$ ed., RS Cotran, V Kumar, and SL Robins (eds). Sauders Company, Philadelphia. 1-35. 1994.

28. Boelsterli UA and Zbinden G. Early biochemical and morphological changes of the rat adrenal medulla induced by xylitol. Arch Toxicol. 57: 25-30. 1985.

29. Bär A. Sugars and adrenal proliferative lesions: The effects of lactose and various polyalcohols. J Am Coll Toxicol. 7: 71-81. 1988.

30. Tischler AS, Powers JF, Pignatello M, Tsokas P, Downing JC, and McClain RM. Vitamin D3-induced Proliferative lesions in the rat adrenal medulla. Toxicol Sci. 51: 9-18. 1999.

31. Kurokawa Y, Hayashi Y, Maekawa A, Takahashi M, and Kukubo T. High incidences of pheochromocytomas after long-term administration of retinol acetate to F344/DuCrj rats. J Natl Cancer Inst. 74: 715-723. 1985. 